\title{
1. Introducing the book: the what, why and how of relevance and impact
}

\author{
Friederike Welter, David Urbano, Turki
}

Alfahaid, Abdullah Aljarodi, Elsa Breit, Andreas Buhrandt, Débora de Castro Leal, Sina Feldermann, Jonas Janisch, Philipp Köhn, Tatiana Lopez, Anne Löscher, Anna Müller, Max Paschke, Philipp Julian Ruf, Julia Schnittker and Christine Weigel

In this chapter, as an introduction to the whole book, we will briefly discuss the what and why of relevance and impact in doctoral research, touching upon questions of definitions and interpretations, why research matters, and the challenges in making it matter.

\section{UNDERSTANDING IMPACT AND RELEVANCE}

We start with a quick look at what constitutes relevance and impact. There has been a flurry of articles, books and editorials on relevance and impact of research over the past decade, showing that scholars have started to care, once more, about the outcomes of their research and the value they may generate for businesses, managers, society, or economic and social development (to name but a few from management and entrepreneurship: see Flickinger et al. 2014; Frank and Landström 2016; George 2016; Kieser et al. 2015; Landström et al. 2017b; Van de Ven and Johnson 2006; Whitehurst and Richter 2018). This literature also illustrates how difficult it is to disentangle the two concepts: relevance and impact. Therefore, our intention is not to conduct a definitional debate, but we do want to outline the main concepts and interpretations we have identified in academia, which also arose in discussions between the late career researchers (Friederike and David) and early career researchers (the rest of the author group) when writing this introductory chapter.

Impact can be a first step on our way towards relevance. Not surprisingly, academics tend to focus on scholarly impact, also because this appears easy 
to measure. Podsakoff et al. (2018, p. 498) suggest research as highly impactful that 'expands and deepens our understanding of important phenomena, addresses significant gaps in the literature, influences the nature and direction of the topics thought to be important in the field, and stimulates thinking and conversations about the topic of interest'. Whilst their understanding also can apply to considering which research is relevant to practitioners and policymakers, the authors, however, go on to suggest a narrow indicator for measuring that impact, namely the number of citations an article receives in the Web of Science databases. Scholarly impact adds to academic legitimacy - both individually and for organisations (Flickinger et al. 2014) - but whether legitimacy automatically also signals that research is relevant, we believe is open to debate. In her account of academic management research that matters, Anita McGahan (2007, p. 751) reflects

[. . .] on draft managerial articles by academics I had seen that ultimately were not published, or were published but did not have the impact that the authors envisioned. Many of the papers were academically rigorous - typically they were more rigorously researched than those that were successful ultimately. Almost all had compelling messages. The reasons for their failure of impact reflect a range of circumstances, including managerial apathy and complex implications. Yet the most salient common thread was that the papers did not offer managers integrative solutions to relevant and narrowly defined problems.

Telling, isn't it? Both of the senior authors of this chapter could add their own experiences of topics that are considered academically interesting, but that are of little or no value to practitioners and policymakers. And not just that, striving for impact in this narrow sense may lead to research focusing on organisational phenomena mostly 'uncoupled from the real world' (Tushman and O'Reilly III 2007). In the worst case, this might result in 'bad management theories [that] are [. . .] destroying good management practices' (Ghoshal 2005, p. 86). We have become 'gap-spotters' (Landström et al. 2017a) and restricted the impact our field could have.

Of course, scholarly impact is important, especially in the early stages of a research career. And 'gap-spotting' also is one of the strategies employed by new researchers (and often recommended by supervisors to doctoral students) to identify potential research themes. But we urge you to not stop there. Without considering the 'real world' implications of what we have decided to study and publish in highly ranked journals, scholarly impact will remain just that: in most cases, a journal article which has received many citations has probably also won one of the impact or best paper awards and is therefore seen as impactful from a scholarly viewpoint, but this may be within a bounded small (or large) academic community. 
What, then, is research relevance? Whilst scholarly impact in a narrow sense is reduced to citations and similar measures, we also can think of scholarly impact as research that questions the assumptions of our models and theories, introduces novel research methodologies that have in-built interactions with practitioners - in short: research that pushes the boundaries of our current knowledge, similar to the understanding of Podsakoff et al. (2018) mentioned earlier. Others consider slightly different facets of relevance. For example, Alvesson et al. (2017) point to meaning as elementary for relevance which is about conducting research that is meaningful to the individual (the researcher), academic organisations (a university, academia) and wider society. 'Relevant research begins with and pursues a research question with impact' (Wiklund et al. 2019, p. 427). Such research matters, because it cares about and involves the different groups we want to serve: ourselves with a career and professional status to achieve; students (Aguinis et al. 2019); academia in general; practitioners and policymakers; and wider society. This also implies that we should not (solely) ask what society can offer us researchers (Alvesson et al. 2017), but pay much more attention to what we can offer to society.

\section{WHY DO RELEVANCE AND IMPACT MATTER?}

Is our concern with relevance and impact an ivory tower of theoretical discussion? Why should we care; why does this discussion matter? Is there enough consideration of relevance/impact in academia? To start with, there are two main reasons why we should care about the relevance and impact of our research. Society demands it and academic organisations have started to enforce it. Society needs answers, answers to grand challenges like the climate catastrophe and economic development in a world which increasingly leaves behind some of its member states or groups of people within societies and which destroys the foundation of their living. Academia can provide some answers or at least attempt to contribute to some of those grand challenges. Also, most societies pay for academia, through taxes - and therefore academia should feel obliged to give back.

Academic organisations have started to pay closer attention to the relevance issue. Over time, universities have changed, and nowadays most higher education organisations recognise their responsibility towards society. 'Third task', 'third mission', 'societal mission', are some of the labels used by higher education organisations to name their efforts in reaching out to society and transferring research results. While technology or research transfer offices have a long history, 'third task' efforts explicitly encompass all disciplines at a higher education organisation and aim to go beyond simple technology transfer, patenting of research results, or new venture creation based on research results. 
For those employed in academic organisations, this implies motivation to deliver not only academic output such as articles, research reports and the like, but also to think about the implications of their research for society and the economy. Why, we could ask ourselves, should governments (and taxpayers) fund researchers if they won't contribute to social progress and create relevant new knowledge? It is time for academics to leave their beloved ivory tower - again. Entrepreneurship researchers, especially, have a history of reaching out to the subjects they study; and the popularity of the sector has been explained as a result of it being an interesting research field as well as generating important insights for society and policy (Frank and Landström 2016). However, over time, as entrepreneurship research has matured as a field and gained academic legitimacy, we seem to have forgotten the practice 'out there' which was such a distinctive characteristic during the early stages of entrepreneurship (and in particular small business) research (Baker and Welter 2015). Frank and Landström (2016, p. 53) argue that 'Institutionalization [of a research field] favours rigour at the cost of relevance, while at the same time rigour promotes the institutionalization of research fields.' In the case of entrepreneurship research, this meant institutionalisation in business schools and management departments, going hand in hand with a preference for the narrow view of scholarly impact as main indicator for relevance. Alvesson et al. (2017) suggest that these developments are part of the reason why the social sciences have lost their meaning. They critique the current focus on publishing, which has pushed many researchers to set aside their passion for science and to focus on learning the rule of 'science as a game'. That is what Palmer (2006, pp. 548, 550) called a 'silent majority' of academics not giving voice to research which is 'motivated by the desire to develop knowledge that can improve [...] practice' in order to get published.

Notwithstanding institutional and academic pressures, academics continue to be intrinsically motivated, understanding their own responsibility as reaching beyond academic publishing and educating the next generation of students. One of the protagonists in Strelecky's (2012) novel questions if today is a good museum day. Experiences and moments of one's own life are exhibited in this personal life museum; and every day influences the exhibitions there. Transferred to science and the influence of academia on society, one might ask the question as to which exhibition in a large museum I would like to work on. With what knowledge and images should the museum of my department/ research area be filled? Or even, which contribution of my field of research will be on view in the Museum of World History? And who would like to visit this museum and why? How will the contributors of the museum be seen? As part of Palmer's silent majority or ones who have raised their voices? If we answer these questions today for tomorrow, we will have an idea of why relevance and influence are significant and how we can make a difference. 
Leaving the ivory tower and caring about our relevance beyond conference presentations and publications will add to our legitimacy in the 'real world' outside academia. Otherwise, we might end up in a self-referencing system where 'The ivory tower discusses whether the ivory tower is an ivory tower' as the book contributors quipped during one of their seminars. Discussions with policymakers, presenting results to entrepreneurs or those supporting them, is a-sometimes harsh - reality check for our research findings, but it also adds to our legitimacy - and consequently to society's willingness to continue funding the 'ivory tower'.

\section{WHICH ARE THE CHALLENGES TO MAKE RELEVANCE AND IMPACT HAPPEN?}

Academics face several challenges in trying to make their research impactful and relevant. From the perspective as head of a policy-oriented research institute (Friederike), there are four major pitfalls: time scales, academic independence, what counts as evidence, and the difficulties involved in communicating with policymakers because of differing expectations about what can be done with research results. First, academia and policymakers have different time scales, with the latter needing results and implications quickly, whilst academics often need time to grasp new and unknown themes and to accumulate empirical evidence. Also, academia needs to keep its independence, because otherwise, research results may be perceived as being tainted. Academics are not lobbyists. Advising policymakers can be compared to a tightrope walk: it is a delicate balance between keeping a researcher's integrity and using one's in-depth knowledge of what has worked beforehand to present (potential) solutions to new problems and circumstances. Finally, one of the biggest challenges is the communication with, in this case, policymakers. Trained as researchers, we have entirely different ways of communicating and writing we talk differently, we use jargon (not that policymakers don't use their own of course) - and it takes quite a while to bridge this communication gap. For example, we need to make sure that we find our own authentic way of talking to policymakers; we need to know how far we can take our empirical evidence; and we must be independent enough to resist adhering to the demands of policymakers to make our evidence fit their expectations.

These are generic challenges that also apply to taking our research to practitioners and entrepreneurs. Wiklund et al. (2019, p. 427) rightly conclude that we cannot " force" our insights onto entrepreneurs and policymakers, but have to appeal to the things that they care deeply about'. It is a question of shifting perspectives, about trying to understand 'the other side' which makes more practitioner-related or policy-oriented research work often incompatible with a focus on high scholarly impact. 
Add to that the challenges arising from within academia which include balancing the demands of our disciplines and disciplinary traditions with the demands of our organisations and the outside world. Some of our disciplines appear to be more suited to interactions with practitioners and policymakers. Others have a pronounced tendency to focus on scholarly impact as an indicator for relevance, neglecting the 'outside' world. We believe that disciplines become more inward-looking over time, as they mature, which results in equating relevance more with scholarly impact and less with reaching out to practitioners of all sorts. Economics, for example, is often (too) inward-looking and streamlined, valuing scholarly impact over conversations with practitioners and policymakers, and caught in niche discussions around theories, methodologies and modelling that are devoid of any realist content and bear little, if any, relevance to the real world.

Leaving the ivory tower and talking to the outside world is a challenge, but fruitful: it helps in generating new research ideas (and also may facilitate access to research funding); it is our reality check, and, as stated in the previous section, it is our responsibility and an essential part of our task. For early career researchers, however, it is even more challenging to balance writing a doctoral thesis and developing a research portfolio in order to gain standing as an academic in a discipline with reaching out to practice and being relevant beyond academia. For those who want to continue in academia there is persistent pressure to publish (i.e. the focus on scholarly impact), but at times, the passion for research may suffice for the former but not the latter option (or vice versa). But we believe that change within our organisations and regarding our rules for tenure and academic promotion can only happen if we all - early, mid and late career researchers - promote the need for relevance as the basis for impactful research.

Relevance and impact depend heavily on perspective and context. When one travels by train and looks out of the window to the left and right, one will see unordered relevant fields (research fields) that one may want to interact with. Or we can look at the earth from a spaceship and perceive and define fields differently. On his recent space mission, ESA astronaut and geophysicist Alexander Gerst (2018) apologised from outer space to the next generations and promised to make a liveable future possible. We should take this to heart, not least because future generations will not be interested in why we did something, but they will question why we did not act in the face of an imminent environmental catastrophe. Research is not just about getting published in the best management and entrepreneurship journals, but is also about sustaining our societies and the world - and each piece of research may contribute a little piece to the bigger puzzle. For this we need to take a step back from the silent majority of academics and raise our voices. We suggest a call for more academic (transdisciplinary) collaborations, for maintaining our scientific curios- 
ity and for asking not only 'which topic is hot enough to be publishable in the best journals', but also 'which topic serves our stakeholders best', and all that despite any pressures we may be subject to from our institutional employers.

The chapters in this book will therefore consider different ways of making research relevant - with relevance understood in its wider meaning, including both scholarly impact as well as relevance to those we want to serve with our research. We will examine new research directions, relevant research approaches and issues of transferring research results. Come join us - let's open the Trojan Horses within our ivory tower and start moving out!

\section{REFERENCES}

Aguinis, Herman, Ravi S. Ramani, Nawaf Alabduljader, James R. Bailey and Joowon Lee (2019), 'A pluralist conceptualization of scholarly impact in management education: Students as stakeholders', Academy of Management Learning \& Education, 18 (1), 11-42.

Alvesson, Mats, Yiannis Gabriel and Roland Paulsen (2017), Return to Meaning: A Social Science with Something to Say, Oxford: Oxford University Press.

Baker, Ted and Friederike Welter (2015), 'Bridges to the future', in Ted Baker and Friederike Welter (eds), The Routledge Companion to Entrepreneurship, London: Routledge, pp. 3-17.

Flickinger, Miriam, Anja Tuschke, Tina Gruber-Muecke and Marina Fiedler (2014), 'In search of rigor, relevance, and legitimacy: What drives the impact of publications?', Journal of Business Economics, 84 (1), 99-128.

Frank, Hermann and Hans Landström (2016), 'What makes entrepreneurship research interesting? Reflections on strategies to overcome the rigour-relevance gap', Entrepreneurship \& Regional Development, 28 (1-2), 51-75.

George, Gerard (2016), 'Management research in AMJ: Celebrating impact while striving for more', Academy of Management Journal, 59 (6), 1869-77.

Ghoshal, Sumantra (2005), 'Bad management theories are destroying good management practices', Academy of Management Learning and Education, 4 (1), 75-91.

Kieser, Alfred, Alexander Nicolai and David Seidl (2015), 'The practical relevance of management research: Turning the debate on relevance into a rigorous scientific research program', The Academy of Management Annals, 9 (1), 143-233.

Landström, Hans, Annaleena Parhankangas, Alain Fayolle and Philippe Riot (2017a), 'Institutionalization of entrepreneurship as a scholarly field', in Hans Landström, Annaleena Parhankangas, Alain Fayolle and Philippe Riot (eds), Challenging Entrepreneurship Research, London, New York: Routledge, pp. 1-17.

Landström, Hans, Annaleena Parhankangas, Alain Fayolle and Philippe Riot (eds), (2017b), Challenging Entrepreneurship Research, London, New York: Routledge.

McGahan, Anita M. (2007), 'Academic research that matters to managers: On zebras, dogs, lemmings, hammers, and turnips', Academy of Management Journal, 50 (4), 748-53.

Palmer, Donald (2006), 'Taking stock of the criteria we use to evaluate one another's work: ASQ fifty years out', Administrative Science Quarterly, 51 (4), 535-59.

Podsakoff, Philip M., Nathan P. Podsakoff, Paresh Mishra and Carly Escue (2018), 'Can early-career scholars conduct impactful research? Playing "small ball" versus 
"swinging for the fences", Academy of Management Learning \& Education, 17 (4), 496-531.

Strelecky, J. P. (2012), The Big Five for Life, Florida: Aspen Light Publishing.

Tushman, M. and Charles O'Reilly III (2007), 'Research and relevance: Implications of Pasteur's quadrant for doctoral programs and faculty development', Academy of Management Journal, 50 (4), 769-74.

Van de Ven, Andrew H. and Paul E. Johnson (2006), 'Knowledge for theory and practice', Academy of Management Review, 31 (4), 802-21.

Whitehurst, Fiona and Paul Richter (2018), 'Engaged scholarship in small firm and entrepreneurship research: Grappling with Van de Ven's diamond model in retrospect to inform future practice', International Small Business Journal, 36 (4), 380-99.

Wiklund, Johan, Mike Wright and Shaker A. Zahra (2019), 'Conquering relevance: Entrepreneurship research's grand challenge', Entrepreneurship Theory \& Practice, 43 (3), 419-36.

\section{Web References}

Gerst, Alexander (2018), 'Nachricht an meine Enkelkinder', YouTube channel of the European Space Agency, 19 December, accessed 17 September 2019 at https://www .youtube. $\mathrm{com} /$ watch? $\mathrm{v}=4$ UfpkRFPIJk. 